Proceedings of the 8th Polish Symposium of Physics in Economy and Social Sciences FENS, Rzeszów, November 4-6, 2015

\title{
Numerical Analysis of Modified Kaldor-Kalecki Model with Couplings and Delays
}

\author{
B. JaCKOWSKA-ZDUniak, A. OrŁOWski \\ Faculty of Applied Informatics and Mathematics, Warsaw University of Life Sciences - SGGW \\ Nowoursynowska 159, 02-776 Warszawa, Poland
}

\begin{abstract}
Modified Kaldor-Kalecki-type model of business cycles with delays are considered. Unidirectional and bidirectional couplings are introduced to investigate relationships between three "global" markets and two "local" markets. Selected results of an extensive numerical analysis are presented.
\end{abstract}

DOI: 10.12693/APhysPolA.129.1008

PACS/topics: 89.65.Gh, 88.05.Lg, 05.45.-a, 02.60.Lj, 05.45.Xt

Investigations of macroeconomic cycles have a quite long and interesting history, see [1-3] for details. It seems that especially fruitful are various versions and generalizations of Kaldor-Kalecki models [4-7]. Quite recently we have proposed another generalization that takes into account the interactions between two economies [8]. Such interactions are inevitable in real life situations and in the present paper we develop a more realistic model of three "global" and two "local" economies mutually interacting in a way resembling actual economical influences and relationships between countries on the global market.

Let us consider five "economies", each characterized by a pair $\left(y_{i}, y_{i+1}\right)$, where the first element $y_{i}$ stands for the gross domestic product (GDP), the second element $y_{i+1}$ is the capital stock, and $\mathrm{i}=1,3,5,7,9$. Three of these systems, namely $\left(y_{1}, y_{2}\right),\left(y_{7}, y_{8}\right)$, and $\left(y_{9}, y_{10}\right)$ represent "global" economies, say the European Union, China, and the USA, respectively. The remaining two systems: $\left(y_{3}, y_{4}\right)$ and $\left(y_{5}, y_{6}\right)$ represent "local" economies, say, Poland and Germany. Later on we will justify such a choice by a proper adjustment of relevant parameters.

Following our previous arguments [8] we construct a set of ten equations describing five mutually interacting economies with delays and both unidirectional and bidirectional couplings:

$$
\begin{aligned}
& \dot{y}_{1}=\alpha_{1}\left(F_{1}(t)-\delta_{1} y_{2}(t)-\gamma_{1} y_{1}(t)\right), \\
& \dot{y}_{2}=F_{1}(t-\tau)-\delta_{1} y_{2}(t-\tau)-\delta y_{2}(t) \\
& \quad-s_{5}\left(y_{9}(t)-y_{1}(t)\right)+s_{6}\left(y_{7}(t)-y_{1}(t)\right), \\
& \dot{y}_{3}=\alpha_{2}\left(F_{2}(t)-\delta_{2} y_{4}(t)-\gamma_{2} y_{3}(t)\right), \\
& \dot{y}_{4}=F_{2}(t-\tau)-\delta_{2} y_{4}(t-\tau)-\delta y_{4}(t)-s_{2}\left(y_{1}(t)\right. \\
& \left.\quad-y_{3}(t)\right)+s_{10}\left(y_{7}(t)-y_{3}(t)\right)-s_{12}\left(y_{5}(t)-y_{3}(t)\right), \\
& \dot{y}_{5}=\alpha_{3}\left(F_{3}(t)-\delta_{3} y_{6}(t)-\gamma_{3} y_{5}(t)\right), \\
& \dot{y}_{6}=F_{3}(t-\tau)-\delta_{3} y_{6}(t-\tau)-\delta y_{6}(t)-s_{3}\left(y_{1}(t)\right. \\
& \left.\quad-y_{5}(t)\right)+s_{9}\left(y_{7}(t)-y_{5}(t)\right)-s_{13}\left(y_{3}(t)-y_{5}(t)\right),
\end{aligned}
$$

$$
\begin{aligned}
& \dot{y}_{7}=\alpha_{4}\left(F_{4}(t)-\delta_{4} y_{8}(t)-\gamma_{4} y_{7}(t)\right), \\
& \dot{y}_{8}=F_{4}(t-\tau)-\delta_{4} y_{8}(t-\tau)-\delta y_{8}(t)-s_{8}\left(y_{9}(t)\right. \\
& \left.\quad-y_{7}(t)\right)-s_{11}\left(y_{1}(t)-y_{7}(t)\right), \\
& \dot{y}_{9}=\alpha_{5}\left(F_{5}(t)-\delta_{5} y_{10}(t)-\gamma_{5} y_{9}(t)\right), \\
& \dot{y}_{10}=F_{5}(t-\tau)-\delta_{5} y_{10}(t-\tau)-\delta y_{10}(t)-s_{4}\left(y_{1}(t)\right. \\
& \left.\quad-y_{9}(t)\right)+s_{7}\left(y_{7}(t)-y_{9}(t)\right) .
\end{aligned}
$$

Here $F_{i}(t)(i=1, \ldots, 5)$ are the investment functions, $s_{j}(j=2, \ldots, 13)$ are the coupling coefficients, $\alpha_{k}(k=$ $1, \ldots, 5)$ are the adjustment coefficients in the good market, $\delta \in(0,1)$ is the depreciation rate of capital stock, $\gamma_{l}$ $(l=1, \ldots, 5)$ and $\delta_{m}(m=1, \ldots, 5)$ are constants, and $\tau$ is a time delay fixed at $\tau=3$.

We assume that the investment functions for global markets such as the European Union, Chinese, and American economy have logistic character, but the investment function for local markets have trigonometric characteristics, i.e., for Poland we use a sine and for Germany we have a hyperbolic tangent. Thus $F_{1,4,5}(t)=\mathrm{e}^{y_{1,7,9}(t)} /\left(1+\mathrm{e}^{y_{1,7,9}(t)}\right), F_{2}(t)=0.8 \sin \left(y_{3}(t)\right)$, and $F_{3}=0.5 \operatorname{tgh}\left(y_{5}(t)\right)$. Being global or local economy is determined by respective values of $\alpha_{k}$ parameters, for which we make a natural assumption that this correction factor for the stronger market is equal to or greater than an analogous coefficient corresponding to the weaker market.

In further numerical analysis of the above defined system of equations we carefully choose the values of all parameters to maximally resemble the real economic situation and to preserve relationships known to be present in the real economic life.

First let us try "to calibrate" the model by assuming no couplings (so all coefficients $s_{j}$ are set equal to zero). Taking into account the real values of gross domestic products of five considered countries we make the following substitutions for parameters $\alpha_{k}: \alpha_{1}=4, \alpha_{2}=2$, $\alpha_{3}=3, \alpha_{4}=3.5$, and $\alpha_{5}=3.8$. We fix the values of 


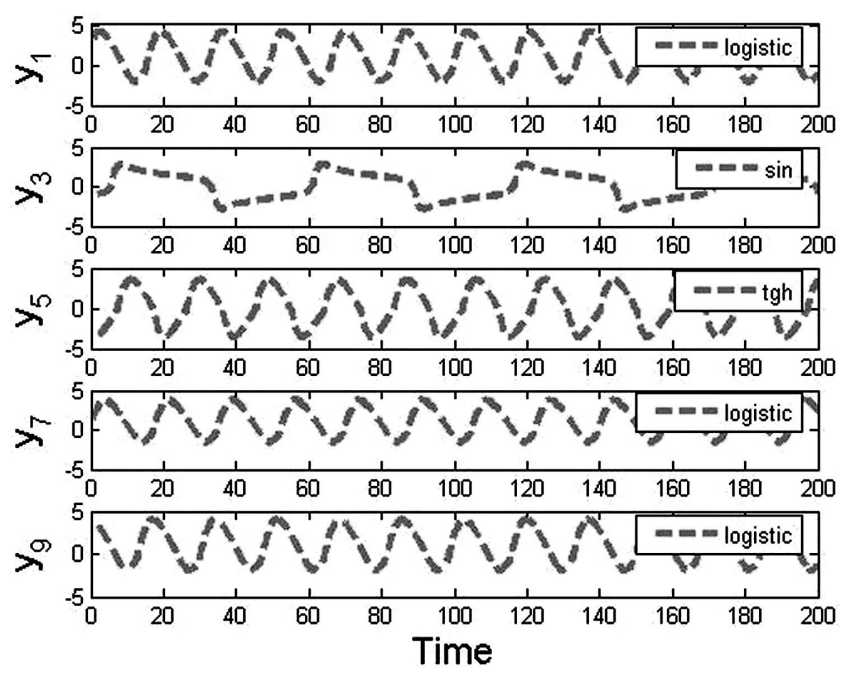

Fig. 1. Independent cycles of GDP dynamics for five investigated economies, no couplings.

the remaining parameters which are not so crucial for interpretation, as follows: $\delta=0.1$, all $\gamma_{l}=0.2$ and all $\delta_{m}=0.2$. Results of numerical simulations presented in Fig. 1 are very convincing - we reveal well developed separated business cycles for each economy, as could be expected.

Now we are ready to enrich the model with coupling coefficients. We assume there is no direct individual influence of Polish and German economy on the European Union as a whole and that there is no direct influence of the USA economy on Poland and Germany (only via the European Union).

We use bidirectional coupling between Germany and Poland (coefficients $s_{12}$ and $s_{13}$ ). For over 20 years, Germany has been the most important Polish trade partner and now has about $26 \%$ share in Polish exports and approximately $22 \%$ share of imports. The role of Poland in German trade is also quite reasonable. It takes 8th position in the ranking of German export-import turnover, ahead of Switzerland, Belgium and Spain. The values of these coefficients are estimated from public data of export-import in 2014. We also use bidirectional coupling between the USA and the European Union (coefficients $s_{4}$ and $s_{5}$ ). The United States are most important trading partner of the UE. Economic relations between the parties are very intense and financial markets are deeply integrated. The EU investment in the US are eight times higher than the EU investments in China and India together, and American investments in Europe are three times bigger than in the whole of Asia. Influence of the EU on China is described by $s_{11}$ and its impact on Polish and German economies by $s_{2}$, and $s_{3}$, respectively. We use bidirectional coupling between China and the USA: in the last decade, the US economy was growing largely thanks to Chinese credits, and China developed thanks to the demand of American consumers. The USA is the largest recipient of Chinese products, and China is the largest lender and investor in the US government bonds. These dependencies are described by coefficients $s_{7}$ and $s_{8}$.

Of course, today, there is no economy, which would not be linked to the Chinese market in some way. China affects the prices of everyday products, inflation, the profitability of debt securities, the level of interest rates, real estate prices, labor costs, and raw material prices. Therefore we assume that China affects each of the remaining five economies (coefficients $s_{6}, s_{9}, s_{10}$, and $s_{11}$ ).
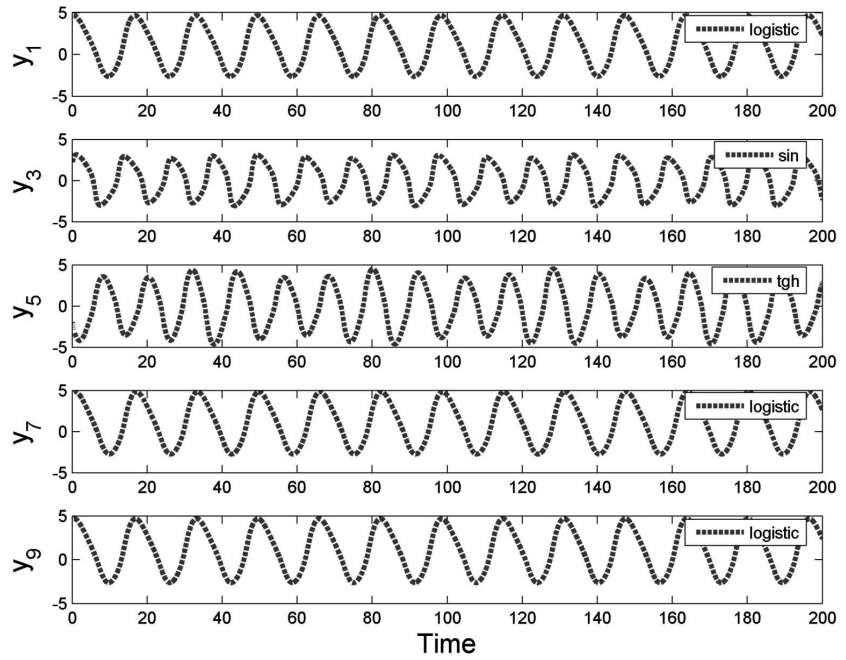

Fig. 2. GDP dynamics for five investigated economies, with couplings.

Taking into account all the above considerations and data available we assign to the coupling coefficients the following values: $s_{2}=0.1, s_{3}=0.05, s_{4}=0.05, s_{5}=0.1$, $s_{6}=0.2, s_{7}=0.3, s_{8}=0.2, s_{9}=0.1, s_{10}=0.05$, $s_{11}=0.2, s_{12}=0.25, s_{13}=0.2$. In Fig. 2 we present results of numerical simulations for this case (couplings switched on and all other parameters kept the same as in the previous no-coupling situation).

It is clear from the obtained results that the investigated model of the mutual interactions of five economic systems is able to correctly predict the basic features of the complicated real market dynamics. Our simple model seems to be complex enough and our choice of its parameters is realistic enough to provide very good qualitative agreement of obtained numerical results with economic reality. Therefore in a future publication we plan to perform much more involved simulations within this approach to elaborate various complicated scenarios of global market dynamics. In that way we do hope to discover some new phenomena of the interrelated global economy. 


\section{References}

[1] J.A. Schumpeter, Business Cycles, A Theoretical, Historical, and Statistical Analysis of the Capitalist Process, McGraw-Hill Book Company, New York 1939.

[2] Kyun Kim, Equilibrium Business Cycle Theory from Historical Perspective, Cambridge University Press, Cambridge 1988.

[3] V. Zarnowitz, Business Cycles: Theory, History, Indicators, and Forecasting, The Chicago University Press, Chicago 1996.
[4] M. Kalecki, Econometrica 3, 327 (1935).

[5] N. Kaldor, Econ. J. 50, 78 (1940).

[6] A. Krawiec, M. Szydłowski, Ann. Oper. Res. 89, 89 (1999).

[7] A. Krawiec, M. Szydłowski, J. Nonlinear Math. Phys. 8, 266 (2001).

[8] B. Jackowska-Zduniak, U. Grzybowska, A. Orłowski, Acta Phys. Pol. A 127, A-70 (2015). 